\title{
HARTOG (François), SCHMITT (Pauline), SCHNAPP (Alain), éds., Pierre Vidal-Naquet, un historien dans la cité
}

Paris, La Découverte, 1998, 228 p. (postface de Jean-Pierre Vernant)

\section{Régine Azria}

\section{(2) OpenEdition \\ Journals}

Édition électronique

URL : http://journals.openedition.org/assr/20309

DOI : 10.4000/assr.20309

ISSN : $1777-5825$

Éditeur

Éditions de l'EHESS

Édition imprimée

Date de publication : 31 décembre 2000

Pagination : 95-96

ISBN : 2-222-96698-1

ISSN : 0335-5985

\section{Référence électronique}

Régine Azria, «HARTOG (François), SCHMITT (Pauline), SCHNAPP (Alain), éds., Pierre Vidal-Naquet, un historien dans la cité », Archives de sciences sociales des religions [En ligne], 112 I octobre-décembre 2000, document 112.25, mis en ligne le 19 août 2009, consulté le 21 septembre 2020. URL : http:// journals.openedition.org/assr/20309; DOI : https://doi.org/10.4000/assr.20309 


\section{HARTOG (François), SCHMITT (Pauline), SCHNAPP (Alain), éds., Pierre Vidal-Naquet, un historien dans la cité}

Paris, La Découverte, 1998, 228 p. (postface de Jean-Pierre Vernant)

Régine Azria

\section{RÉFÉRENCE}

HARTOG (François), SCHMITT (Pauline), SCHNAPP (Alain), éds., Pierre Vidal-Naquet, un historien dans la cité, Paris, La Découverte, 1998, 228 p. (postface de Jean-Pierre Vernant)

1 Plus qu'hommage ou simple témoignage d'amitié, ce recueil autour de la personne, de l'œuvre et des engagements de P.V.N., nous plonge au cœur des questions que l'histoire de ce siècle pose à chacun d'entre nous, questions relatives à la morale civique, à la vérité, à la mémoire. Plus que d'autres, la guerre d'Algérie, la Deuxième Guerre mondiale et l'extermination des juifs sont des tranches d'histoire que P.V.N. vit en direct. La première parce qu'il y inaugure sa carrière d'intellectuel engagé, la seconde parce que « l'intérêt qu'(il) porte au génocide des juifs s'appuie sur un noyau essentiel : celui de sa propre vie dont le cours a en quelque sorte été détourné par les années noires » (A. Wieviorka). La déportation de ses parents n'est en effet pas étrangère à la démarche historienne et militante qui lui est propre et qui l'amène à verser au service d'une même cause - la dénonciation du négationnisme - mémoire individuelle et familiale et archives historiques.

2 Trois parties articulent ce livre où amis, collègues et témoins se passent le relais de la plume. Dans la première, "L'intellectuel dans la cité », sont évoqués les engagements de P.V.N. face à la guerre d'Algérie, à la torture, au mensonge d'État (contributions de M. Rebérioux, L. Schwartz, R. Bonnaud. M. Bénabou, P. Pachet). On sait qu'alors, le 
jeune intellectuel des années 1950 qui milite contre la guerre d'Algérie et qui. face à une justice baillonnée, se fait pour la circonstance enquêteur et juge d'instruction dans l'Affaire Audin, annonce déjà l'historien chevronné des années 1980, engagé dans une " guérilla harassante contre les négationnistes ». « Faire reconnaître les faits, faire que les témoins soient entendus, aura été le sens de plusieurs des grands combats du siècle » écrit P. Pachet. C'est celui, en tout cas, que mène inlassablement P.V.N.

Les contributions rassemblées dans la seconde partie, "L'historien de l'Antiquité ", (contributions de Ch.Segal, Cl. Mossé, Ch. Malamoud, J. Brunschwig, O. Murray) montrent qu'en étudiant la société antique et ses institutions, P.V.N., manifeste, de fait, sa volonté d'agir sur le présent. "Sa conception de l'histoire, écrit O. Murray, fonctionne comme un modèle et une critique des temps modernes et justifie les efforts de l'historien pour influencer le cours des événements de son temps ". C'est aussi la volonté de déconstruire une Grèce idéalisée qui amène l'historien critique à s'intéresser aux groupes opprimés au sein de la culture dominante : l'esclave, la femme, l'artisan, ou encore à s'intéresser à ces figures des frontières que sont l'éphèbe et l'étranger dans la tragédie grecque (Ch. Segal). Par ailleurs, si l'analyse des mythes intéresse P.V.N. c'est, entre autres, parce qu'ils sont révélateurs d'une manière de penser la société, car qu'il s'agisse de la Grèce antique ou du sionisme, P.V.N. est toujours «attentif au jeu des forces mentales dans l'histoire » (I. Malkin).

un souci constant de relier passé et présent, de mettre en perspective historique pour des lecteurs d'aujourd'hui (un aujourd'hui qui doit lui-même être périodiquement mis à jour), est également évoqué le compagnonnage ininterrompu entre histoire et philosophie ; en exergue de sa contribution, son parent et ami J. Brunschwig cite cette phrase ironique et provocatrice de P.V.N.: « on ne peut se baigner deux fois dans le même fleuve, dit le philosophe, mais l'historien peut remonter le cours du temps ».

5 C'est dans la troisième partie, "Les Juifs, la mémoire, le présent » (contributions de F. Schmidt, A. Wieviorka, I. Malkin) que le tissage permanent entre histoire et mémoire s'impose avec le plus de force. À propos du génocide, l'événement à l'origine de la brisure qui s'est produite dans sa vie le jour où ses parents sont arrêtés par la gestapo, P.V.N. n'hésite pas à solliciter sa mémoire personnelle et familiale, au titre de témoin de l'histoire. Là, évidemment, s'impose «l'exigeante nécessité de construire ou reconstruire son objet en maîtrisant son propre imaginaire, en tendant, même s'il sait pertinemment que c'est de façon asymptotique, à la vérité » (A. Wieviorka). Historien engagé dans la cité, P.V.N. travaille dans l'urgence, toujours attentif à l'immédiat, mais sans jamais s'y enfermer.

Riche de contenu, d'estime et d'amitié, l'ensemble n'épuise évidemment ni l'œuvre, ni la liste des engagements de l'homme. 